\title{
Cost-effectiveness analysis of first and second-generation EGFR tyrosine kinase inhibitors as first line of treatment for patients with NSCLC harboring EGFR mutations
}

\author{
Oscar Arrieta ${ }^{1 *}$ (D, Rodrigo Catalán', Silvia Guzmán-Vazquez², Feliciano Barrón', Luis Lara-Mejía',
} Herman Soto-Molina ${ }^{2}$, Maritza Ramos-Ramírez ${ }^{1}$, Diana Flores-Estrada ${ }^{1}$ and Jaime de la Garza ${ }^{1}$

\begin{abstract}
Background: Tyrosine-kinase inhibitors (TKIs) have become the cornerstone treatment of patients with non-small cell lung cancer that harbor oncogenic EGFR mutations. The counterpart of these drugs is the financial burden that they impose, which often creates a barrier for accessing treatment in developing countries. The aim if the present study was to compare the cost-effectiveness of three different first and second generation TKIs.

Methods: We designed a retrospective cost-effectiveness analysis of three different TKIs (afatinib, erlotinib, and gefitinib) administered as first-line therapy for patients with NSCLC that harbor EGFR mutations.

Results: We included 99 patients with the following TKI treatment; 40 treated with afatinib, 33 with gefitinib, and 26 with erlotinib. Median PFS was not significantly different between treatment groups; 15.4 months (95\% Cl 9.319.5) for afatinib; 9.0 months ( $95 \% \mathrm{Cl} 6.3-\mathrm{NA}$ ) for erlotinib; and 10.0 months ( $95 \% \mathrm{Cl} 7.46-14.6)$ for gefitinib. Overall survival was also similar between groups: 29.1 months (95\% Cl 25.4-NA) for afatinib; 27.1 months (95\% Cl 17.1- NA) for erlotinib; and 23.7 months ( $95 \% \mathrm{Cl} 18.6-\mathrm{NA})$ for gefitinib. There was a statistically significant difference between the mean TKls costs; being afatinib the most expensive treatment. This difference was observed in the daily cost of treatment $(p<0.01)$, as well as the total cost of treatment $(p=0.00095)$. Cost-effectiveness analysis determined that afatinib was a better cost-effective option when compared with first-generation TKls (erlotinib and gefitinib).
\end{abstract}

Conclusion: In our population, erlotinib, afatinib, and gefitinib were statistically equally effective in terms of OS and PFS for the treatment of patients with advanced EGFR-mutated NSCLC population. Owing to its marginally increased PFS and OS, the cost-effectiveness analysis determined that afatinib was a slightly better cost-effective option when compared with first-generation TKIs (erlotinib and gefitinib).

Keywords: Lung adenocarcinoma, Treatment cost, Cost-effectiveness, Economic burden

\footnotetext{
* Correspondence: ogar@unam.mx

'Thoracic Oncology Unit, Instituto Nacional de Cancerología, San Fernando

No. 22, Col. Sección XVI, Del. Tlalpan, CP. 14080 Mexico City, Mexico

Full list of author information is available at the end of the article
}

C C The Author(s). 2020 Open Access This article is licensed under a Creative Commons Attribution 4.0 International License, which permits use, sharing, adaptation, distribution and reproduction in any medium or format, as long as you give appropriate credit to the original author(s) and the source, provide a link to the Creative Commons licence, and indicate if changes were made. The images or other third party material in this article are included in the article's Creative Commons licence, unless indicated otherwise in a credit line to the material. If material is not included in the article's Creative Commons licence and your intended use is not permitted by statutory regulation or exceeds the permitted use, you will need to obtain permission directly from the copyright holder. To view a copy of this licence, visit http://creativecommons.org/licenses/by/4.0/. The Creative Commons Public Domain Dedication waiver (http://creativecommons.org/publicdomain/zero/1.0/) applies to the data made available in this article, unless otherwise stated in a credit line to the data. 


\section{Background}

Lung cancer is the leading cause of cancer-related deaths worldwide; among lung cancer types, the most frequently diagnosed is non-small cell lung cancer (NSCL C), which globally represents $85 \%$ of lung cancer cases. In 2018 GLOBOCAN reported an incidence for NSCLC of 7811 cases and an associated mortality of 6733 patients in Mexico, representing the sixth most commonly diagnosed neoplasia and third most common cause of cancer related-deaths [1]. At diagnosis, many patients with NSCLC are already in an advanced disease stage (IIIB or IV) and thus, they are ineligible for surgical resection. Therefore, the public health impact of lung cancer should be considered as a widespread problem that affects developed as well as developing countries [2]. Apart from the deleterious prognosis that lung cancer imposes, the financial burden that is associated with this neoplasia is overwhelming.

In the last decade treatment of patients with advanced NSCLC improved at an increased pace. The recognition of activating mutations and other biomarkers resulted in a paradigm shift for the treatment strategies of these tumors [3]. Currently, most patients with NSCLC receive a treatment scheme that includes targeted therapies such as EGFR tyrosine kinase inhibitors (TKI), immunotherapy, VEGF inhibitors or combination strategies [4]. These novel drugs have improved the prognosis of disease; however, their cost is significantly higher than the cost of previously used conventional chemotherapy.

Mutations of the gene EGFR are present on approximately $10-20 \%$ of patients with NSCLC, and in over $50 \%$ of patients with adenocarcinoma, which is the most frequent subtype among NSCLCs $(45-55 \%)[5,6]$. TKIs, such as gefitinib, erlotinib, and afatinib, are the cornerstone drugs for the first-line treatment of patients with NSCLC harboring EGFR oncogenic mutations. Efficacy of first (gefitinib and erlotinib) and second-generation (afatinib) TKIs has been widely validated elsewhere [710]; it has been demonstrated that when used as firstline therapy in patients with advanced EGFR-mutated NSCLC the overall response rate (ORR) is $\sim 70-80 \%$, and the median progression-free survival (PFS) is $10-12$ months $[10,11]$.

Recently, osimertinib a third-generation EGFR-TKI has demonstrated an overall survival benefit in the first-line setting against gefitinib or erlotinib, becoming the new standard of treatment in some developed countries [12, 13]. Nevertheless, osimertinib has not demonstrated to be cost-effective in most of the analyses conducted. Therefore, first-generation TKIs are still widely prescribed.

Even though the benefits of TKIs are enormous, the counterpart of these drugs is the financial burden that they impose. Additionally, TKIs are administered until disease progression or unacceptable toxicity, without any predetermined time of therapy, which further increases the cost of treatment [14]. The aim of this study was to retrospectively evaluate the cost-effectiveness of three different TKIs (afatinib, erlotinib, and gefitinib) in patients with EGFR-mutated NSCLC from a single tertiary-care medical center located at a developing country.

\section{Methods}

\section{Study design}

We developed a retrospective cost-effectiveness analysis of three different TKIs (afatinib, erlotinib, and gefitinib) administered as first-line therapy for patients with NSCL $\mathrm{C}$ that harbor EGFR mutations. For this analysis, we performed a Markov modeling with three possible patient health statuses: progression-free, progression of disease, or death.

\section{Data collection}

Medical records from every patient with NSCLC and mutated EGFR, that received treatment at Instituto Nacional de Cancerología (INCan) at Mexico City, between January of 2013 and December of 2016, were reviewed. This was an observational study that did not jeopardized patients clinical management and or identity; therefore, approval by the ethics committee of INCan and signature of informed consent were both waived.

Analyzed data included: age, gender, Karnofsky performance status, ECOG performance status, biomass exposure, smoking history, diabetes mellitus, arterial hypertension, TKI therapy and adverse reactions to treatment (type, grade, duration, associated treatment and the treatment for adverse events). Data collection was performed between August of 2016 and June of 2017. Medical records from patients were excluded if the medical record was unable to report at least $80 \%$ of previously determined variables.

\section{Evaluation of monetary expenditure and cost- effectiveness analysis}

Monetary expenditure estimation was developed by including the cost of corresponding TKI (afatinib, erlotinib or gefitinib); for this task, we considered the acquisition costs at which INCan purchased the drug (TKI). We also estimated the associated costs for treatment of unwanted effects that were related to each therapy; including medical visits and drugs used to palliate adverse effects, according to a preestablished INCan price list.

For the cost-effectiveness analysis, we calculated the Incremental Cost-Effectiveness Ratio (ICER), which is a summary measure representing the economic value of an intervention compared with an alternative. ICER was calculated with the following formula: 
Table 1 Cost of Afatinib, Erlotinib, and Gefitinib; and indicated dosage

\begin{tabular}{llll}
\hline TKI & Presentation & $\begin{array}{l}\text { Cost at which INCan bought one } \\
\text { month of treatment }\end{array}$ & $\begin{array}{l}\text { Daily } \\
\text { dose }\end{array}$ \\
\hline Afatinib & $\begin{array}{l}30 \text { tablets of } \\
40 \mathrm{mg}\end{array}$ & MXN 22,950.00 & $40 \mathrm{mg}$ \\
Erlotinib & 30 tablets of & MXN 24,560.40 & \\
& $150 \mathrm{mg}$ & & 150 \\
Gefitinib & 30 tablets of & MXN 13,532.04 & $\mathrm{mg}$ \\
& $250 \mathrm{mg}$ & & 150 \\
\end{tabular}

ICER $=($ Treatment 1 -Treatment 2$) /($ Effectiveness 1 -Effectiveness 2$)$

ICER reflects the cost per unit of effectiveness increased; if ICER stands below the acceptability threshold it can be assumed that the analyzed treatment is an appropriate cost-effectiveness option. For this study, the acceptability threshold was defined as the annual gross domestic product (GDP) per capita in Mexico; at the time of analysis, annual per capita GDP was 8902 USD. At a currency exchange of MXN 17.8 for each USD, the annual GDP was equivalent to MXN 158,455.00.

\section{Statistical analysis}

For descriptive purposes, continuous variables were summarized as arithmetic means and standard deviations (SD), categorical variables were comprised as frequencies and proportions. Overall survival (OS), and progression-free survival (PFS) were analyzed by the Kaplan-Meier method. Statistical significance was predetermined to be present for values of $p<0.05$ based on a two-sided test.

For deterministic sensitivity analysis, the time horizon was considered at 3 and 5 years, and the discount rate was determined according to the recommendations of the Conduction of Economic Evaluation Studies of the

Table 2 General characteristics of population

\begin{tabular}{|c|c|c|c|c|}
\hline & $\begin{array}{l}\text { Population } \\
\boldsymbol{N}=99\end{array}$ & $\begin{array}{l}\text { Afatinib } \\
\boldsymbol{N}=40\end{array}$ & $\begin{array}{l}\text { Erlotinib } \\
\boldsymbol{N}=26\end{array}$ & $\begin{array}{l}\text { Gefitinib } \\
\boldsymbol{N}=33\end{array}$ \\
\hline \multicolumn{5}{|l|}{ Gender } \\
\hline - Women & $73(73.7 \%)$ & 28 (70.0\%) & $22(84.6 \%)$ & $23(69.7 \%)$ \\
\hline - Men & $26(26.3 \%)$ & $12(30.0 \%)$ & $4(15.4 \%)$ & $10(30.3 \%)$ \\
\hline Age (years) & $61.2(14.0)$ & $57.925(14.5)$ & $64.3(12.8)$ & $62.8(14.0)$ \\
\hline Stage IV NSCLC & $83(83.8)$ & $33(82.5)$ & $22(84.61)$ & $28(84.84)$ \\
\hline Current or former smoker & $22(22.2 \%)$ & $3(11.5 \%)$ & $4(12.1 \%)$ & $15(15.2 \%)$ \\
\hline Woodsmoke exposure & $16(16.2 \%)$ & $4(15.4 \%)$ & $6(18.2 \%)$ & $16(16.2 \%)$ \\
\hline \multicolumn{5}{|l|}{ Karnofsky } \\
\hline$\cdot 50$ & $2(2.2 \%)$ & $1(2.6 \%)$ & $1(4.2 \%)$ & $0(0.0 \%)$ \\
\hline .60 & $3(3.2 \%)$ & $2(5.3 \%)$ & $0(0.0 \%)$ & $1(3.2 \%)$ \\
\hline$\cdot 70$ & $12(12.9 \%)$ & $4(10.5 \%)$ & $4(16.7 \%)$ & $4(12.9 \%)$ \\
\hline$\cdot 80$ & $33(35.5 \%)$ & $14(36.8 \%)$ & $7(29.2 \%)$ & $12(38.7 \%)$ \\
\hline$\cdot 90$ & $38(40.9 \%)$ & $16(42.1 \%)$ & $12(50 \%)$ & $10(32.3 \%)$ \\
\hline$\cdot 100$ & $5(5.4 \%)$ & $1(2.6 \%)$ & $0(0.0 \%)$ & $4(12.9 \%)$ \\
\hline - Not Reported & 6 & 2 & 2 & 2 \\
\hline \multicolumn{5}{|l|}{ ECOG } \\
\hline .0 & $2(2.2 \%)$ & $0(0.0 \%)$ & $0(0.0 \%)$ & $2(6.5 \%)$ \\
\hline$\cdot 1$ & 75 (81.5\%) & 34 (91.9\%) & $18(75.0 \%)$ & $23(74.2 \%)$ \\
\hline$\cdot 2$ & $12(13.0 \%)$ & $2(5.4 \%)$ & $4(16.7 \%)$ & $6(19.4 \%)$ \\
\hline$\cdot 3$ & $3(3.3 \%)$ & $1(2.7 \%)$ & $2(8.3 \%)$ & $0(0.0 \%)$ \\
\hline - Not Reported & 7 & 3 & 2 & 2 \\
\hline Diabetes Mellitus & $17(17.2 \%)$ & $5(12.5 \%)$ & $5(19.2 \%)$ & 7 (21.2\%) \\
\hline Arterial hypertension & $23(23.2 \%)$ & $8(20.0 \%)$ & 7 (26.9\%) & $8(24.2 \%)$ \\
\hline \multicolumn{5}{|l|}{ EGFR Mutation } \\
\hline - EGFR del 19 & $25(25.3 \%)$ & $12(30.0 \%)$ & $5(19.2 \%)$ & $8(24.2 \%)$ \\
\hline - EGFR L858R & 67 (67.7\%) & 27 (67.5\%) & $16(61.5 \%)$ & $24(72.7 \%)$ \\
\hline - Non-reported & $7(7.1 \%$ & $1(2.5 \%)$ & $5(19.2 \%)$ & $1(3.0 \%)$ \\
\hline
\end{tabular}




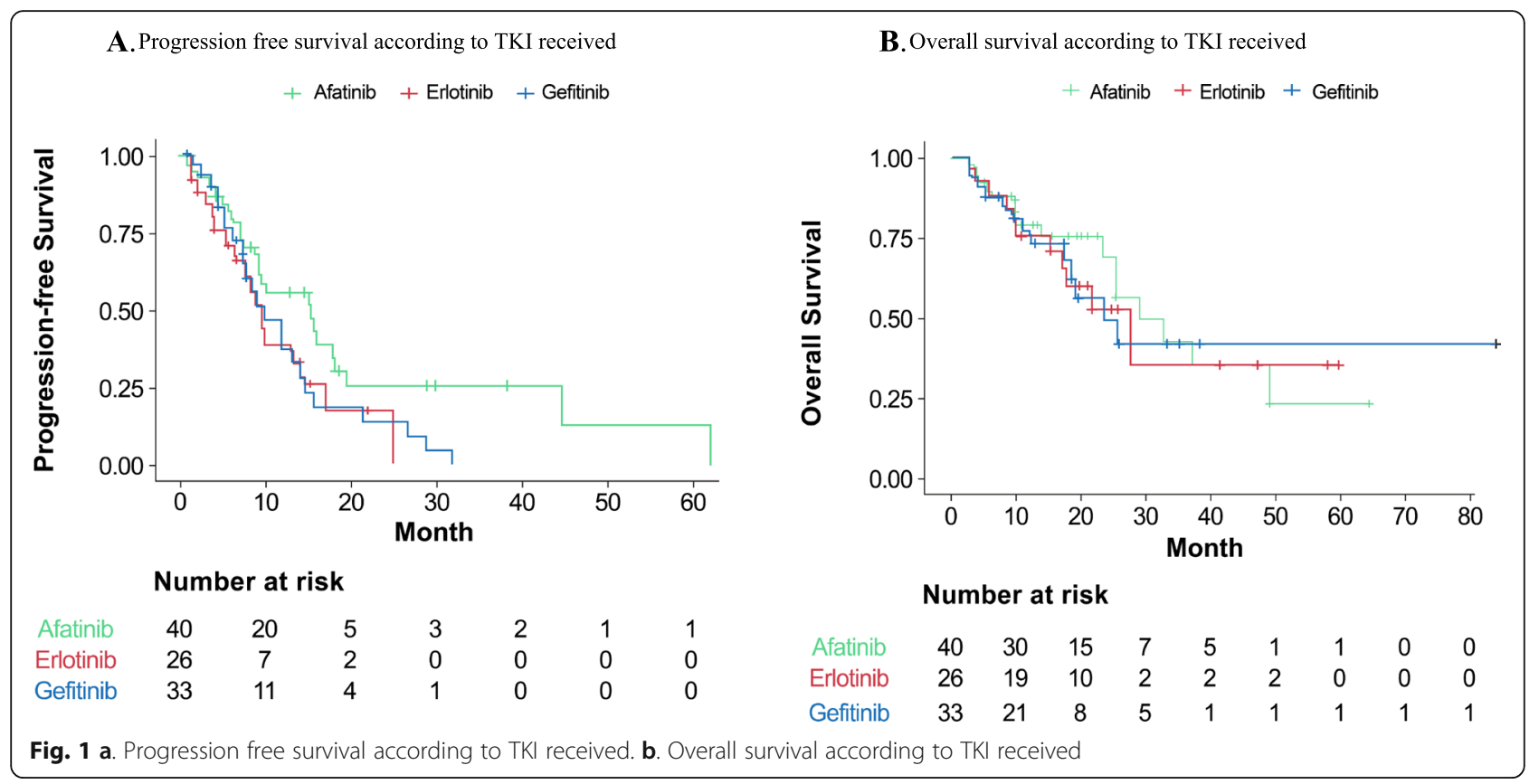

National Health Council guidelines. The deterministic sensitivity analysis was carried out considering the casebase of a $5 \%$ discount rate, also using 0,3 , and $7 \%$, discount rates, as well as a probabilistic sensitivity analysis using Monte Carlo simulations. In total, 1000 simulation samples were randomly taken from the distributions, and each time, the model results (incremental costs and incremental effects) were recalculated.
All statistical analyses were carried out using the $R$ software (version 3.6.2).

\section{Results}

We included 99 patients with the following TKI treatment; 40 treated with afatinib, 33 with gefitinib, and 26 with erlotinib. The cost of TKIs, and treatment dosage

Table 3 Percentage of patients that developed adverse effects to TKI

\begin{tabular}{|c|c|c|c|c|c|c|}
\hline \multirow[t]{2}{*}{ Unwanted effect } & \multicolumn{2}{|c|}{ Afatinib $(n=40)$} & \multicolumn{2}{|c|}{ Erlotinib $(n=26)$} & \multicolumn{2}{|c|}{ Gefitinib ( $n=33$ ) } \\
\hline & Any Grade & Grade 3-4 & Any Grade & Grade 3-4 & Any Grade & Grade 3-4 \\
\hline Any unwanted effect & $36(90 \%)$ & $3(7.5 \%)$ & $26(100 \%)$ & $4(15.4 \%)$ & $26(78.8 \%)$ & $1(3 \%)$ \\
\hline · Rash & $23(57.5 \%)$ & $1(2.5 \%)$ & $13(50 \%)$ & $1(3.8 \%)$ & $13(39.4 \%)$ & $0(0.0 \%)$ \\
\hline - Diarrhea & $14(35 \%)$ & $2(5 \%)$ & $13(50 \%)$ & $2(7.7 \%)$ & $18(54.5 \%)$ & $0(0.0 \%)$ \\
\hline - Xerosis & $16(40 \%)$ & $0(0.0 \%)$ & $9(34.6 \%)$ & $0(0.0 \%)$ & $12(36.4 \%)$ & $0(0.0 \%)$ \\
\hline - Paronychia & $11(27.5 \%)$ & $0(0.0 \%)$ & $4(15.4 \%)$ & $0(0.0 \%)$ & $4(12.1 \%)$ & $0(0.0 \%)$ \\
\hline - Nausea & $3(7.5 \%)$ & $0(0.0 \%)$ & 7 (26.9\%) & $0(0.0 \%)$ & $7(21.2 \%)$ & $0(0.0 \%)$ \\
\hline - Acne & $6(15 \%)$ & $0(0.0 \%)$ & $6(23.1 \%)$ & $0(0.0 \%)$ & $1(3 \%)$ & $0(0.0 \%)$ \\
\hline - Fatigue & $5(12.5 \%)$ & $0(0.0 \%)$ & $6(23.1 \%)$ & $0(0.0 \%)$ & $2(6.1 \%)$ & $0(0.0 \%)$ \\
\hline - Stomatitis & $6(15 \%)$ & $0(0.0 \%)$ & $5(19.2 \%)$ & $0(0.0 \%)$ & $5(15.2 \%)$ & $0(0.0 \%)$ \\
\hline - Constipation & $2(5 \%)$ & $0(0.0 \%)$ & $4(15.4 \%)$ & $0(0.0 \%)$ & $3(9.1 \%)$ & $0(0.0 \%)$ \\
\hline - Vomit & $2(5 \%)$ & $0(0.0 \%)$ & $3(11.5 \%)$ & $0(0.0 \%)$ & $1(3 \%)$ & $0(0.0 \%)$ \\
\hline - Alopecia & $1(2.5 \%)$ & $0(0.0 \%)$ & $0(0 \%)$ & $0(0.0 \%)$ & $3(9.1 \%)$ & $1(3 \%)$ \\
\hline - Neuropathy & $2(5 \%)$ & $0(0.0 \%)$ & $0(0 \%)$ & $0(0.0 \%)$ & $3(9.1 \%)$ & $0(0.0 \%)$ \\
\hline - Anorexia & $3(7.5 \%)$ & $0(0.0 \%)$ & $0(0 \%)$ & $0(0.0 \%)$ & $1(3 \%)$ & $0(0.0 \%)$ \\
\hline - Liver toxicity & $0(0 \%)$ & $0(0.0 \%)$ & $1(3.8 \%)$ & $0(0.0 \%)$ & $0(0 \%)$ & $0(0.0 \%)$ \\
\hline - Anemia & $0(0 \%)$ & $0(0.0 \%)$ & $0(0 \%)$ & $0(0.0 \%)$ & $1(3 \%)$ & $0(0.0 \%)$ \\
\hline - Arthralgia & $1(2.5 \%)$ & $0(0.0 \%)$ & $0(0 \%)$ & $0(0.0 \%)$ & $1(3 \%)$ & $0(0.0 \%)$ \\
\hline
\end{tabular}


used are shown in Table 1. Population baseline characteristics are presented in Table 2.

Median PFS was not significantly different between treatment groups; 15.4 months (95\% CI 9.3-19.5) for afatinib; 9.0 months (95\% CI 6.3- NA) for erlotinib; and 10.0 months (95\% CI 7.46-14.6) for gefitinib. Overall survival was also similar between groups: 29.1 months (95\% CI 25.4-NA) for afatinib; 27.1 months (95\% CI 17.1- NA) for erlotinib; and 23.7 months (95\% CI 18.6NA) for gefitinib. Kaplan Meyer curves of PFS and OS are presented in Fig. 1 a and b, respectively.

Adverse effects were present in $90 \%$ of patients treated with afatinib, $96.2 \%$ of patients treated with erlotinib, and $79 \%$ of patients treated with gefitinib. There were no statistically significant differences among adverse effects frequency between groups. Frequencies and grade of unwanted effects are presented at Table 3.

\section{Cost analysis results}

Total and daily costs associated exclusively with each TKI is presented as mean, median, and range for each treatment group on Table 4 . There was a statistically significant difference between the mean TKIs costs; being afatinib the most expensive treatment. This difference was observed in the daily cost of treatment $(p<0.01)$, as well as the total cost of treatment $(p=0.00095)$. The costs related to unwanted effects are also presented in Table 4. There were no statistically significant differences among total costs (medications plus medical visits) associated with unwanted effects between treatment groups. The total monetary cost of TKI plus unwanted effects was significantly higher in patients treated with afatinib.

\section{Cost-effectiveness analysis}

Results from the cost-effectiveness analysis are presented at Table 5 .

As it can be seen, gefitinib has better effectiveness and lower cost than erlotinib; therefore, it can be stated that erlotinib is dominated by gefitinib in our costeffectiveness analysis. Accordingly, any further analysis will only compare gefitinib and afatinib. While analyzing ICER between afatinib and gefitinib we can observe that afatinib is a better cost-effectiveness option when compared to gefitinib; this is because the obtained ICER is below the acceptability threshold, which was determined to be the annual GDP per capita in Mexico. By extended dominance, it could be assumed that afatinib is also a better cost-effective option than erlotinib.

\section{Deterministic sensitivity analysis}

A deterministic sensitivity analysis was carried out upon the base case of a $5 \%$ discount rate, also using 0,3 , and $7 \%$ discounts. The results of this analysis for PFS are shown in Table 6.

The univariate deterministic sensitivity analysis showed that for PFS, changing the discount rate does not modify the case-base results, reflecting robustness of the results from our analysis.

A probabilistic sensitivity analysis was also performed where a probabilistic distribution was assigned to health costs and results, considering a hypothetical cohort of 1000 patients via Monte-Carlo simulation; these results are presented at Table 7 .

\section{Discussion}

Treatment of patients with EGFR-mutated NSCLC has been revolutionized by TKIs, which are a clear example of the clinical benefit of target therapies. Albeit, the cost of these drugs is sometimes the greatest obstacle for obtaining this kind of treatment $[14,15]$. In this retrospective study, we aimed to analyze the cost of therapy, the associated cost of treating unwanted effects related to therapy and the cost-effectiveness of three different TKIs; namely, erlotinib, gefitinib, and afatinib.

As our results suggest, all three studied TKIs are equally effective, with similar PFS and OS. We also noticed similar rates of unwanted effects in all the groups.

Table 4 Cost of TKI therapy and cost of related unwanted effects (UE). Amounts are presented in MXN pesos

\begin{tabular}{|c|c|c|c|c|c|c|c|}
\hline & \multicolumn{2}{|l|}{$\begin{array}{l}\text { Afatinib } \\
(n=40)\end{array}$} & \multicolumn{2}{|l|}{$\begin{array}{l}\text { Erlotinib } \\
(n=26)\end{array}$} & \multicolumn{2}{|l|}{$\begin{array}{l}\text { Gefitinib } \\
(n=33)\end{array}$} & \multirow[t]{2}{*}{$p$-value } \\
\hline & Mean (SD) & Median & Mean (SD) & Median & Mean (SD) & Median & \\
\hline \multicolumn{8}{|l|}{ TKI cost } \\
\hline Daily cost & $722(130)$ & 765 & $794(96)$ & 819 & $451(0)$ & 451 & $<0.001$ \\
\hline Total cost & $337,325(299,832)$ & 238,298 & $200,506(137,831)$ & 183,384 & $149,645(107,139)$ & 126,299 & $<0.001$ \\
\hline \multicolumn{8}{|l|}{ UE cost } \\
\hline Medications & $6846(21,203)$ & 2485 & 3479 (5727) & 897 & $2212(4762)$ & 98 & $<0.05$ \\
\hline Consultation & $4373(5751)$ & 1732 & 3797 (4382) & 2598 & 4304 (6125) & 1732 & 0.843 \\
\hline Total & $11,219(23,734)$ & 6948 & 7276 (8498) & 5267 & 6516 (8986) & 2719 & 0.262 \\
\hline $\begin{array}{l}\text { TOTAL } \\
\text { TKI + UE }\end{array}$ & $348,544(311,386)$ & 246,258 & $207,782(143,566)$ & 186,685 & $156,161(111,330)$ & 126,299 & $<0.001$ \\
\hline
\end{tabular}


Table 5 Cost-effectiveness analysis results according to PFS and OS for each treatment group. Amounts are presented in MXN pesos

\begin{tabular}{|c|c|c|c|c|c|}
\hline TKI & Mean total cost & Incremental Cost & Effectiveness & Incremental Effectiveness & ICER \\
\hline \multicolumn{6}{|c|}{ Progression Free Survival (PFS) } \\
\hline Gefitinib & $\$ 161,800$ & & 8.18 & & Lowest cost \\
\hline Erlotinib & $\$ 215,700$ & $\$ 53,900$ & 6.7 & -1.48 & Dominated by gefitinib \\
\hline Afatinib & $\$ 348,200$ & $\$ 186,400$ & 9.46 & 1.28 & $\$ 145,625.00$ vs gefitinib \\
\hline \multicolumn{6}{|c|}{ Overall Survival (OS) } \\
\hline Gefitinib & $\$ 161,800$ & & 27.1 & & Lowest cost \\
\hline Erlotinib & $\$ 215,700$ & $\$ 53,900$ & 21.7 & -5.4 & Dominated by gefitinib \\
\hline Afatinib & $\$ 348,200$ & $\$ 186,400$ & 37.1 & 10 & $\$ 18,640.00$ vs gefitinib \\
\hline
\end{tabular}

These results are consistent with the meta-analysis published by Burotto et al, which reported similar effectiveness and security of afatinib, erlotinib, and gefitinib, while used as first-line therapy for patients with EGFRmutated NSCLC [16]. Similarly, Liang et al. reported that erlotinib, afatinib, and gefitinib have similar effectiveness, however, they found increased toxicities in patients treated with erlotinib and afatinib, especially rash and diarrhea [17].

It is important to underscore that none of the prior mentioned studies was a randomized controlled clinical trial, therefore conclusions should be made cautiously while analyzing their results. The LUX-Lung 7 was the first randomized clinical trial that compared two different TKIs, afatinib versus gefitinib, as first-line therapy in patients with NSCLC with EGFR gene mutations. In this trial, afatinib provided a marginally benefit in PFS and time to a treatment failure when compared with gefitinib; these results demonstrated to be constant in every subgroup, including patients with L858R mutations and those with deletions on exon19. However, differences in the median OS for both arms were not significantly different, and afatinib present more grade $\geq$ 3 adverse events and serious adverse events. In our study, we did not detect significant differences in PFS or OS among the three treatment groups; however, afatinib was associated with the longest median PFS and OS [18].

The cost-effectiveness analysis of frequently prescribed drugs is becoming of great value for oncologists and decision-makers, especially for the new and upcoming drugs [19, 20]. Thus, cost-effectiveness analyses must consider costs of adverse events management, traveling, and productivity losses, besides the acquisition costs. In a European study, afatinib had the highest probability of being cost-effective (43\%) compared to other TKIs

Table 6 Deterministic sensitivity analysis results according to PFS. Amounts are presented in MXN pesos

\begin{tabular}{|c|c|c|c|c|c|}
\hline TKI & Mean total cost & Incremental Cost & Effectiveness & Incremental Effectiveness & ICER \\
\hline \multicolumn{6}{|c|}{$5 \%$ discount (case-base) } \\
\hline Gefitinib & $\$ 161,800.00$ & - & 8.18 & - & - \\
\hline Erlotinib & $\$ 215,700.00$ & $\$ 53,900.00$ & 6.70 & -1.48 & Dominated \\
\hline Afatinib & $\$ 348,200.00$ & $\$ 186,400.00$ & 9.46 & 1.28 & $\$ 145,625.00$ \\
\hline \multicolumn{6}{|c|}{ No discount (0\%) } \\
\hline Gefitinib & $\$ 206,502.36$ & - & 10.44 & - & - \\
\hline Erlotinib & $\$ 275,293.93$ & $\$ 68,791.58$ & 8.55 & -1.89 & Dominated \\
\hline Afatinib & $\$ 444,401.24$ & $\$ 237,898.88$ & 12.07 & 1.63 & $\$ 145,625.00$ \\
\hline \multicolumn{6}{|l|}{$3 \%$ discount } \\
\hline Gefitinib & $\$ 139,570.10$ & - & 7.06 & - & - \\
\hline Erlotinib & $\$ 186,064.71$ & $\$ 46,494.61$ & 5.78 & -1.28 & Dominated \\
\hline Afatinib & $\$ 300,360.38$ & $\$ 160,790.28$ & 8.16 & 1.10 & $\$ 145,625.00$ \\
\hline \multicolumn{6}{|l|}{$7 \%$ discount } \\
\hline Gefitinib & $\$ 115,361.16$ & - & 5.83 & - & - \\
\hline Erlotinib & $\$ 153,791.12$ & $\$ 38,429.96$ & 4.78 & -1.06 & Dominated \\
\hline Afatinib & $\$ 248,261.79$ & $\$ 132,900.62$ & 6.74 & 0.91 & $\$ 145,625.00$ \\
\hline
\end{tabular}


Table 7 Probabilistic sensitivity analysis results according to PFS and OS. Amounts are presented in MXN pesOS

\begin{tabular}{|c|c|c|c|c|c|}
\hline TKI & Mean total cost & Incremental Cost & Effectiveness & Incremental Effectiveness & ICER \\
\hline \multicolumn{6}{|c|}{ Progression Free Survival (PFS) } \\
\hline Gefitinib & $\$ 161,781.47$ & - & 8.180 & - & - \\
\hline Erlotinib & $\$ 218,411.28$ & $\$ 56,629.81$ & 6.701 & -1.48 & Dominated \\
\hline Afatinib & $\$ 347,853.28$ & $\$ 129,442.00$ & 9.457 & 1.28 & $\$ 101,363.54$ \\
\hline \multicolumn{6}{|c|}{ Overall Survival (OS) } \\
\hline Gefitinib & $\$ 157,891.46$ & - & 27.098 & - & - \\
\hline Erlotinib & $\$ 207,416.43$ & $\$ 49,524.98$ & 21.774 & -5.32 & Dominated \\
\hline Afatinib & $\$ 347,423.61$ & $\$ 140,007.18$ & 37.095 & 10.00 & $\$ 14,004.90$ \\
\hline
\end{tabular}

(erlotinib, gefitinib, and osimertinib). Meanwhile, the probability of being cost-effective for gefitinib, erlotinib, and osimertinib was 13,19 , and $26 \%$, respectively, at the Dutch threshold of $€ 80,000 / \mathrm{QALY}$ [21]. In the present study, the cost-effectiveness analysis determined that afatinib was a better cost-effective option when compared with erlotinib and gefitinib at a Mexican threshold of MXN 158,455.

The limitations of our study are the retrospective nature of the design, which might misreport the complete expenditures associated with cancer treatment; besides, being performed at a single healthcare facility from a developing country with a relatively weak economy, the population might significantly differ from populations at first-world countries with more developed healthcare systems, in which many patients count with private healthcare insurance.

To the best of our knowledge, this was the first study in the Latin-American population that compared the cost-effectiveness of first-line treatment TKI's (gefitinib, erlotinib, and afatinib) for EGFR-mutated (exon 19 deletion or exon 21 L858R mutation) NSCLC patients. Furthermore, in our study, we were able to obtain enough statistical power to determine that even if afatinib is the most expensive treatment, the increased monetary expenditure is compensated with increased effectiveness, although this increased effectiveness did not reach statistical significance. These results prevailed at the deterministic and probabilistic sensitivity analysis; therefore, our results should be considered robust.

Regarding osimertinib as an option of treatment, many cost-effective analyses have been performed to determine its cost-effectiveness compared to first and secondgeneration TKIs in the first-line, and after progression to previous TKI treatment in patients harboring a T-790 M resistance EGFR mutation; none of the aforementioned studies have demonstrated that currently osimertinib is a better cost-effective option of treatment [22-24]. Additionally, those studies were developed in financially stronger health-care systems than ours. It should be noted that most of the population in Mexico has an economical access barrier for acquiring osimertinib, which renders first and second generation TKIs as the most frequently used drugs to treat patients with EGFRmutated NSCLC in our country.

\section{Conclusions}

Cost-effectiveness analyses are gaining tremendous relevance, especially while treating patients with limited monetary resources, such as patients treated at our cohort. In our population, erlotinib, afatinib, and gefitinib were equally effective in terms of OS and PFS for the treatment of patients with advanced EGFR-mutated NSCLC population. Moreover, adverse events were not significantly different, rendering their security profiles quite similar. Afatinib was the most expensive drug, however, owing to its increased PFS and OS, the costeffectiveness analysis determined that, in the setting of a developing country with a weak economy, afatinib was a slightly better cost-effective option when compared with first-generation TKIs (erlotinib and gefitinib).

\section{Abbreviations}

EGFR: Epidermal Growth Factor Receptor; TKI: Tyrosine kinase Inhibitor; NSCL C: Non-small Cell Lung Cancer; VEGF: Vascular-endothelial Growth Factor; ORR: Overall Response Rate; PFS: Progression Free Survival; OS: Overall Survival; ICER: Incremental Cost-Effectiveness Ratio; INCan: Insituto Nacional de Cancerología

\section{Acknowledgements}

Rodrigo Catalán is a doctoral student from Programa de Doctorado en Ciencias Biomédicas at Universidad Nacional Autónoma de México (UNAM) and has received a fellowship (944845) from Consejo Nacional de Ciencia y Tecnologia (CONACYT).

\section{Authors' contributions}

OA: Analyzed the data, supervised the entire protocol and wrote the final version of the manuscript. RC \& LLM: Collected data from patients, analyzed data, and wrote the original version of the manuscript. SGV \& HSM:

Reviewed medical charts, analyzed the data and assisted with Figures. FB \& MRR: Collected data from patients, assisted in the final version of this manuscript. DFE: Collected data from patients, assisted in reviewing medical charts. JdIG: Reviewed the entire protocol, assisted in the writing of final version. The content of the manuscript has not been published, or submitted for publication elsewhere. The author(s) read and approved the final manuscript.

Funding

This paper was not funded by any source. 


\section{Availability of data and materials}

All data generated and analyzed during this study are included in this manuscript. Datasets are available through the corresponding author on reasonable request.

\section{Ethics approval and consent to participate}

This study was an observational, retrospective study that did not jeopardize patient's clinical management and/or identity. Therefore, ethical committee approval and signature of informed consent to participate were both waived by the ethics committee of Instituto Nacional de Cancerologia.

\section{Consent for publication}

All authors approved the final version of this manuscript

\section{Competing interests}

Dr. OA reports personal fees from Pfizer, grants and personal fees from Astra Zeneca, grants and personal fees from Boehringer Ingelheim, personal fees from Lilly, personal fees from Merck, personal fees from Bristol Myers Squibb, grants and personal fees from Roche; all of them outside the submitted work; Dr. Herman Soto reports personal fees and grants from AZ, Boehringer, Roche, Bayer, Takeda, Pfizer and Novartis, all of them outside the submited work. All the remaining authors declare no conflict of interest.

\section{Author details}

'Thoracic Oncology Unit, Instituto Nacional de Cancerología, San Fernando No. 22, Col. Sección XVI, Del. Tlalpan, CP. 14080 Mexico City, Mexico. ${ }^{2} \mathrm{HS}$ Estudios Farmacoeconómicos, Mexico City, Mexico.

\section{Received: 6 July 2020 Accepted: 24 August 2020}

Published online: 01 September 2020

\section{References}

1. Bray F, et al. Global cancer statistics 2018: GLOBOCAN estimates of incidence and mortality worldwide for 36 cancers in 185 countries. CA Cancer J Clin. 2018;68:394-424.

2. Arrieta O, et al. Lung Cancer in Mexico. J Thorac Oncol. 2019;14:1695-700.

3. Girdelli C, Rossil A, Carbone DP, Julia Guarize RR. Non-small-cell lung cancer. Nat Rev Dis Prim. 2015;15009.

4. Zhang C, Leighl NB, Wu YL, Zhong WZ. Emerging therapies for non-small cell lung cancer. J Hematol Oncol. 2019;12:1-24.

5. Arrieta O, Anaya P, Morales-Oyarvide V, Ramírez-Tirado LA, Polanco AC. Cost-effectiveness analysis of EGFR mutation testing in patients with nonsmall cell lung cancer (NSCLC) with gefitinib or carboplatin-paclitaxel. Eur J Health Econ. 2016;17:855-63.

6. Rosell $\mathrm{R}$, et al. Screening for epidermal growth factor receptor mutations in lung cancer. N Engl J Med. 2009;361:958-67.

7. Maemondo M, et al. Gefitinib or chemotherapy for non-small-cell lung cancer with mutated EGFR. N Engl J Med. 2010;362:2380-8.

8. Zhou C, et al. Erlotinib versus chemotherapy as first-line treatment for patients with advanced EGFR mutation-positive non-small-cell lung cancer (OPTIMAL, CTONG-0802): a multicentre, open-label, randomised, phase 3 study. Lancet Oncol. 2011;12:735-42.

9. Schuler $\mathrm{M}$, et al. First-line afatinib versus chemotherapy in patients with non-small cell lung cancer and common epidermal growth factor receptor gene mutations and brain metastases. J Thorac Oncol. 2016;11:380-90.

10. Arrieta O, et al. Effect of Metformin Plus Tyrosine Kinase Inhibitors Compared With Tyrosine Kinase Inhibitors Alone in Patients With Epidermal Growth Factor Receptor-Mutated Lung Adenocarcinoma: A Phase 2 Randomized Clinical Trial [published online ahead of print, 2019 Sep 5]. JAMA Oncol. 2019;5(11):e192553.

11. Franek J, Cappelleri JC, Larkin-Kaiser KA, Wilner KD, Sandin R. Systematic review and network meta-analysis of first-line therapy for advanced -positive non-small-cell lung cancer. Future Oncol. 2019;15:2857-71.

12. Soria JC, et al. Osimertinib in untreated EGFR-mutated advanced non-smallcell lung cancer. N Engl J Med. 2018;378:113-25.

13. Scott LJ. Osimertinib as first-line therapy in advanced NSCLC: a profile of its use. Drugs Ther Perspect. 2018;34:351-7.

14. Wood R, Taylor-Stokes G, Lees M, Chirita O. Cost burden associated with advanced non-small cell lung Cancer (A-NSCLC): impact of disease stage. Value Heal. 2017;20:A427.
15. Arrieta $\mathrm{O}$, et al. Medical care costs incurred by patients with smokingrelated non-small cell lung cancer treated at the National Cancer Institute of Mexico. Tob Induc Dis. 2015;12:1-9.

16. Burotto M, Manasanch EE, Wilkerson J, Fojo T. Gefitinib and Erlotinib in metastatic non-small cell lung Cancer: a meta-analysis of toxicity and efficacy of randomized clinical trials. Oncologist. 2015;20:400-10.

17. Liang $W$, et al. Network meta-analysis of erlotinib, gefitinib, afatinib and icotinib in patients with advanced non-small-cell lung cancer harboring EGFR mutations. PLoS One. 2014;9(2):e85245.

18. Park $K$, et al. Afatinib versus gefitinib as first-line treatment of patients with EGFR mutation-positive non-small-cell lung cancer (LUX-lung 7): a phase 2B, open-label, randomised controlled trial. Lancet Oncol. 2016;17:577-89.

19. Dawe DE, Ellis PM. Challenges in implementing personalized medicine for lung cancer within a national healthcare system. J Pers Med. 2012;2:77-92.

20. Lichtenberg FR. How cost-effective are new cancer drugs in the U.S.? Expert Rev. Pharmacoeconomics Outcomes Res. 2020;20:39-55.

21. Holleman MS, Al MJ, Zaim R, Groen HJM, Uyl-de Groot CA. Costeffectiveness analysis of the first-line EGFR-TKIs in patients with non-small cell lung cancer harbouring EGFR mutations. Eur J Health Econ. 2020;21: 153-64.

22. Aguiar PN, et al. Cost-effectiveness of osimertinib in the first-line treatment of patients with EGFR-mutated advanced non-small cell lung cancer. JAMA Oncol. 2018;4:1080-4.

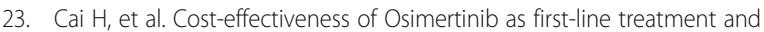
sequential therapy for EGFR mutation-positive non-small cell lung Cancer in China. Clin Ther. 2019:41:280-90.

24. Wu B, Gu X, Zhang Q. Cost-effectiveness of Osimertinib for EGFR mutationpositive non-small cell lung Cancer after progression following first-line EGFR TKI therapy. J Thorac Oncol. 2018;13:184-93.

\section{Publisher's Note}

Springer Nature remains neutral with regard to jurisdictional claims in published maps and institutional affiliations.

\section{Ready to submit your research? Choose BMC and benefit from:}

- fast, convenient online submission

- thorough peer review by experienced researchers in your field

- rapid publication on acceptance

- support for research data, including large and complex data types

- gold Open Access which fosters wider collaboration and increased citations

- maximum visibility for your research: over $100 \mathrm{M}$ website views per year

At BMC, research is always in progress.

Learn more biomedcentral.com/submissions 